Michaelis Pselli Chronographia 


\section{Millennium-Studien}

zu Kultur und Geschichte des ersten Jahrtausends n. Chr.

\section{Millennium Studies}

in the culture and history of the first millennium C.E.

Herausgegeben von / Edited by

Wolfram Brandes, Alexander Demandt, Helmut Krasser, Hartmut Leppin, Peter von Möllendorff, Karla Pollmann

Band 51

De Gruyter 


\title{
Michaelis Pselli Chronographia
}

\author{
Herausgegeben von \\ Diether Roderich Reinsch
}

\author{
Band 1: \\ Einleitung und Text
}

De Gruyter 
Diese Publikation wurde im Rahmen des an der Bayerischen Staatsbibliothek durchgeführten und durch das Bundesministerium für Bildung und Forschung geförderten Vorhabens 16TOA021 - Reihentransformation für die Altertumswissenschaften („Millennium Studien“) mit Mitteln des DFG-geförderten Projekts Fachinformationsdienst Altertumswissenschaften - Propylaeum im Open Access bereitgestellt.

\title{
(c) BY-NC-ND
}

Dieses Werk ist lizenziert unter der Creative Commons Attribution-NonCommercial-NoDerivatives 4.0 International Lizenz. Weitere Informationen finden Sie unter http://creativecommons.org/licenses/by-nc-nd/4.0/.

Die Bedingungen der Creative-Commons-Lizenz gelten nur für Originalmaterial. Die Wiederverwenung von Material aus anderen Quellen (gekennzeichnet mit Quellenangabe) wie z.B. Schaubilder, Abbildungen, Fotos und

Textauszüge erfordert ggf. weitere Nutzungsgenehmigungen durch den jeweiligen Rechteinhaber.

\author{
ISBN 978-3-11-034548-3 \\ e-ISBN (PDF) 978-3-11-034730-2 \\ e-ISBN (EPUB) 978-3-11-038463-5
}

ISSN 1862-1139

\section{Library of Congress Cataloging-in-Publication Data}

A CIP catalog record for this book has been applied for at the Library of Congress.

Bibliographic information published by the Deutsche Nationalbibliothek

Die Deutsche Nationalbibliothek verzeichnet diese Publikation in der Deutschen Nationalbibliografie; detaillierte bibliografische Daten sind im Internet über http://dnb.dnb.de abrufbar.

(C) 2014 Walter de Gruyter GmbH, Berlin/Boston

Die Edition wurde mit dem Classical Text Editor bearbeitet.

Druck und Bindung: Hubert \& Co. GmbH und Co. KG, Göttingen

$\infty$ Gedruckt auf säurefreiem Papier

Printed in Germany

www.degruyter.com 